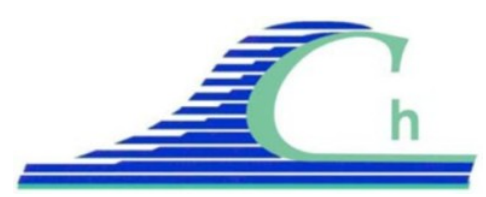

XII ${ }^{\text {ìmes }}$ Journées Nationales Génie Côtier - Génie Civil

Cherbourg, 12-14 juin 2012

DOI:10.5150/jngcgc.2012.015-T @ Editions Paralia CFL

disponible en ligne - http://www.paralia.fr - available online

\title{
Analysis of vertical profiles of mean velocity, shear stress and turbulent viscosity in a wave-current environment through RANS numerical simulations
}

\author{
Maria João TELES ${ }^{1}$, Michel BENOIT ${ }^{2}$, António A. PIRES-SILVA ${ }^{3}$ \\ 1. Instituto Superior Técnico, TULisbon, Av. Rovisco Pais, 1049-001 Lisboa, Portugal. \\ mjteles@gmail.com \\ 2. Saint-Venant Laboratory for Hydraulics (joint research unit between EDF R\&D, \\ CETMEF and Ecole des Ponts ParisTech), 6 quai Watier, BP 49, 78401 Chatou, \\ France. \\ michel.benoit@edf.fr \\ 3. Instituto Superior Técnico, TULisbon, Av. Rovisco Pais, 1049-001 Lisboa, Portugal. \\ aps@civil.ist.utl.pt
}

\begin{abstract}
:
The nearshore hydrodynamics and coastal circulation result from the contribution of a variety of phenomena (large scale circulation currents, tidal effects, waves, wind action, etc.) which have complex physical interactions with different scales. Among these interactions, we focus here on the interaction between waves and currents, especially when the current presents a strong shear over the water depth.

In the present work, the evaluation and analysis of wave-current interactions is made through numerical simulations based on Reynolds Averaged Navier-Stokes (RANS) equations, applied to the modeling of the complete flow motion, namely waves and currents simultaneously (i.e. without decoupling the two phenomena). The advanced CFD solver code_Saturne (ARCHAMBEAU et al., 2004) is used for this purpose.

Numerical results are compared with experimental data from UMEYAMA (2005). Four different wave heights and wave periods for each case of (i) only waves, (ii) waves following currents and (iii) waves opposing currents are tested. A detailed study of the mean horizontal velocities, shear stresses and turbulent viscosity vertical profile changes when waves and currents interact is presented.
\end{abstract}

\section{Keywords:}

Code_Saturne - Wave-current interaction - Reynolds shear stress - Turbulent viscosity

\section{Introduction}

The coastal environment is a complex system where distinct physical processes with different temporal and space scales interact, e.g. large scale circulation currents, tidal effects, waves, wind action. The design of coastal protections and harbour sheltering structures, the evaluation of sediment transport and coastal erosion, the assessment of wave power available at a certain spot or the impact of a farm of wave energy 
converters are examples of possible applications that can benefit from an enhanced knowledge and modelling of these phenomena, and more specifically of wave-current interaction effects.

The work hereby presented is dedicated to the evaluation and analysis of wave-current interactions at a local scale, by focusing on the vertical profiles of mean horizontal velocity, shear stresses and turbulent viscosity. A numerical model based on the Reynolds Averaged Navier-Stokes (RANS) equations is applied to the modelling of the complete flow motion, with waves and currents simultaneously (i.e. without decoupling the two phenomena).

The organization of this paper is as follows. After this introductory section, the experimental data used is described in Section 2. Section 3 presents the numerical model and its settings. Section 4 discusses the results and the findings of the work. Conclusions are summarized in Section 5.

\section{Experimental data}

UMEYAMA (2005) performed a series of experiments, in a channel $25 \mathrm{~m}$ long, $0.7 \mathrm{~m}$ wide and with a water depth of $0.2 \mathrm{~m}$. Regular waves were generated with a piston type wave maker. Wave height and wave period were varied in four tests (labelled T1 to T4) with only waves, waves following currents and waves opposing currents. The mass transport velocity (mean current) in the channel was about $12 \mathrm{~cm} / \mathrm{s}$, either in the same direction as the direction of the waves or in the opposite direction. The forced wave parameters are listed in Table 1 for each test case. Vertical profiles of mean velocity and shear stresses were measured at a distance of $10.5 \mathrm{~m}$ from the wave generator.

Table 1. Wave height and wave period for the four test cases.

\begin{tabular}{lllll}
\hline Tests & T1 & T2 & T3 & T4 \\
\hline Wave height (m) & 0.0202 & 0.0251 & 0.0267 & 0.0280 \\
Wave period (s) & 0.9 & 1.0 & 1.2 & 1.4 \\
\hline
\end{tabular}

\section{Code_Saturne model and setup}

In order to numerically reproduce the experiments from UMEYAMA (2005), we used the RANS CFD solver code_Saturne, developed at Electricité de France (EDF) (ARCHAMBEAU et al., 2004). The RANS equations are written in a conservative form and then integrated over the control volumes of each cell of the $3 \mathrm{D}$ mesh.

$\frac{\partial \rho}{\partial t}+\operatorname{div}(\rho u)=\Gamma$

$\rho \frac{\partial u}{\partial t}+\operatorname{div}(\rho u \otimes u)=-\operatorname{grad}(P)+\operatorname{div}(\tau-\rho R)+S_{u}^{\prime}$

where $\rho$ is the fluid density, $u$ the fluid velocity vector, $\Gamma$ a mass source term, $P$ the pressure, $\tau$ the viscous stress tensor, $R$ the Reynolds stress tensor and $S_{u}$ ' a source term 


\section{XII ${ }^{\text {èmes }}$ Journées Nationales Génie Côtier - Génie Civil \\ Cherbourg, 12-14 juin 2012}

related to the transported quantity $u$. In order to close the system (1) and (2), turbulent correlations have to be modelled. In code_Saturne a number of turbulence closure models are implemented. In this study, a Reynolds Stress Model (RSM) was chosen, namely the $R_{i j}-\varepsilon$ SSG model (SPEZIALE et al., 1991).

Code_Saturne is able to model free surface flows, by using the Arbitrary Lagrangean Eulerian (ALE) method that ensures an accurate representation of the free surface variation. The RANS equations then gain a new term, which is the vertical velocity of the mesh. At each time step the mesh is updated, accordingly.

For the mesh generation it had to be ensured about 10 cells per wavelength to get a good representation of the propagation of the waves. On the other hand, right next to the moving wall corresponding to the wave maker, the mesh velocity had to be compatible with the fluid velocity in order to avoid mesh crossover and the divergence of the simulation. A structured and hexahedral mesh was created with a constant resolution in the $x$ direction of 120 cells over a length of $30 \mathrm{~m}(\Delta x \approx 0.25 \mathrm{~m})$, one single cell in the $y$ (transversal) direction and a variable number in the vertical direction $z$, with a geometric progression of the vertical mesh size $\Delta z$ ranging from $0.002 \mathrm{~m}$ (near the bottom) to $0.005 \mathrm{~m}$ (near the free surface) (cf. figure 1).

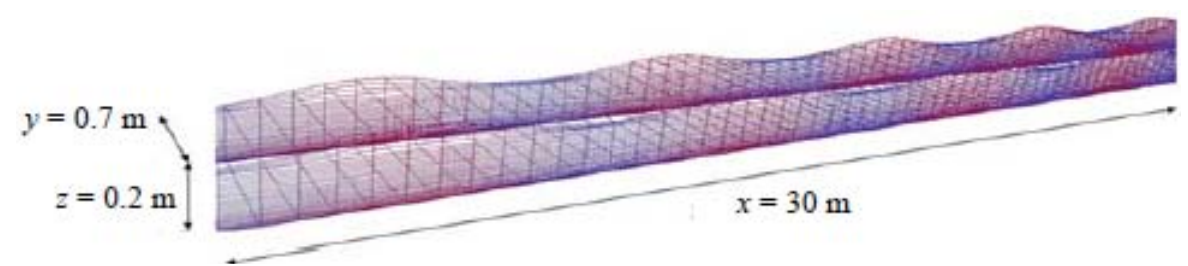

Figure 1. Computational domain representative of experiments from UMEYAMA(2005).

To minimize undesirable super-harmonic free waves, a second order wave board displacement of a piston type (DEAN \& DALRYMPLE, 1991) was applied on the channel at the left lateral boundary. This way, code_Saturne was forced with a horizontal movement of the mesh on the upwave lateral wall aiming to reproduce the waves. The signal had to be progressively imposed at this lateral boundary to avoid a sudden mesh's horizontal movement and thus mesh crossover. The wave reflections at the right end of the channel were dealt with an artificial beach based on a viscous damping term that increased linearly from the bottom to the free surface.

The numerical solution is strongly dependent on the correct imposition of the boundary conditions. An additional condition (3), proposed by CELIK \& RODI (1984), had to be imposed on the free surface for the turbulence closure scheme.

$\varepsilon=\frac{k_{w}^{3 / 2}}{\alpha h}$ 
$\varepsilon$ is the turbulent dissipation, $k_{w}$ the turbulent kinetic energy at the water surface, $\alpha=0.18$ an empirical constant and $h$ the water depth. In the case of the RSM model, $k$ is resolved as the half of the sum of the normal stresses.

With the imposition of this condition, the turbulent dissipation increases and the eddy viscosity decreases towards the free surface. This behaviour was observed in the experiments made by NEZU \& RODI (1986).

\section{Results and discussions}

As specified in section 2, the experiments from UMEYAMA (2005) were made with different wave heights and periods. It should be noted that these experiments do not include a blocking situation of the waves by the current.

The conditions of Table 1 for the four cases were tested in code_Saturne. In the following, comparisons between numerical results and data of the vertical profile of mean horizontal velocity for the tests $\mathrm{T} 1$ and $\mathrm{T} 4$ are shown for only waves (figure 2), waves following current (figure 3), and waves opposing current (figure 4).

Figure 2 shows the vertical profile of the mean horizontal velocity, imposing two different wave heights and periods in a channel without any current. It can be seen that the numerical model predicts quite well the mean horizontal velocity profile for each case. Especially on the test case WW4, which corresponds to a more energetic case, it can be observed that the wave induced streaming near the bottom is very well modelled.
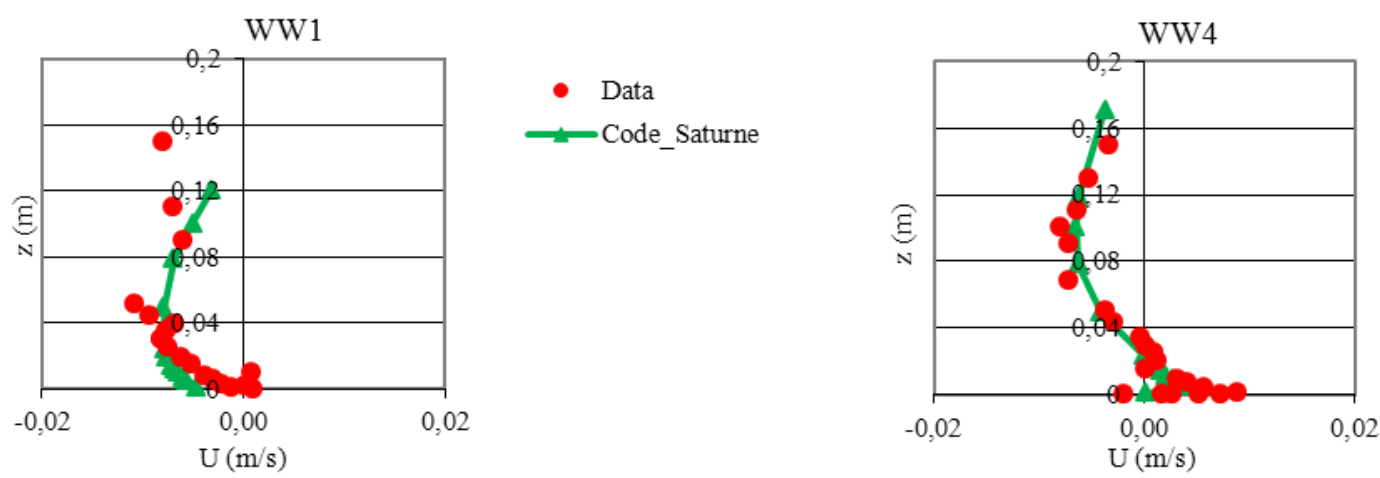

Figure 2. Mean horizontal velocity profiles for only waves: WW1 $(H=0.0202 \mathrm{~m}$; $T=0.9 \mathrm{~s})$ and $W W 4(H=0.0280 \mathrm{~m} ; \mathrm{T}=1.4 \mathrm{~s})$.

In figures 3 and 4 , the mean horizontal velocity vertical profile when waves were superimposed in a turbulent current are shown.

For waves following a current (figure 3) and referring to the only current profile, an increase of the velocity near the bed followed by its reduction near the free surface is observed in the measurements. Both these effects are well reproduced by the model. The other wave heights and periods tested (not shown) exhibit a similar behaviour. 


\section{XII ${ }^{\text {èmes }}$ Journées Nationales Génie Côtier - Génie Civil \\ Cherbourg, 12-14 juin 2012}

As pointed out by OLABARRIETA et al. (2010), the phase averaged Reynolds stresses induced by the waves represent the phase averaged correlation between the horizontal and vertical velocities. In intermediate water depths, like in these experiments, as the wave height increases, so does this correlation and a more intense reduction of the mean horizontal velocity should be noticed. However, as the wave period increases the vertical component of the particle motion decreases, causing a reduction of Reynolds stresses. The effects of the wave height and wave period act in opposing directions and could explain why the reduction near the surface for waves following the current does not change much across the experiments.

For waves opposing currents (figure 4), the main observed feature is the increase of the velocity shear near the free surface. Again the numerical simulations follow closely the experimental data.
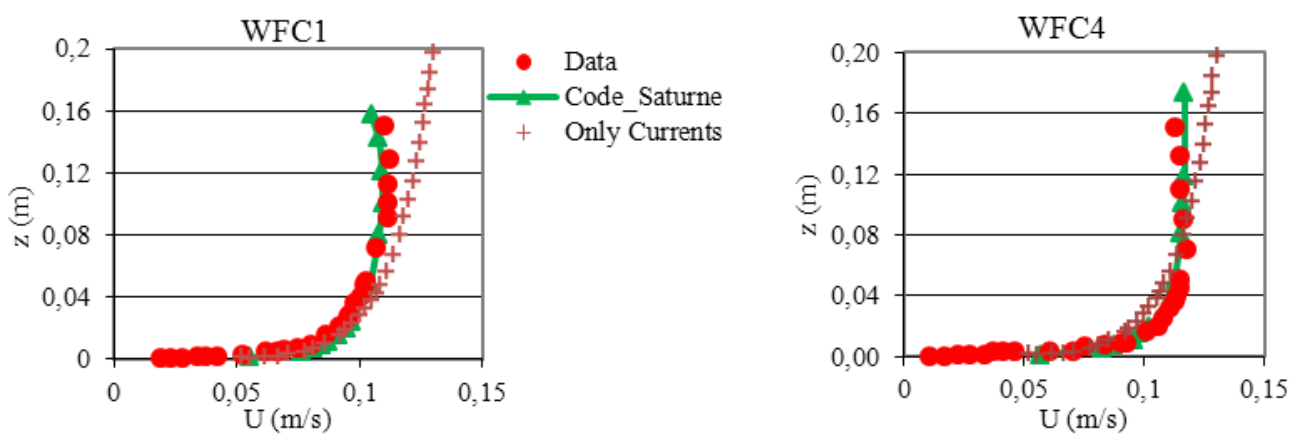

Figure 1. Mean velocity vertical profile for waves following current: WFC1 $(H=0.0202 \mathrm{~m} ; \mathrm{T}=0.9 \mathrm{~s})$ and $\mathrm{WFC} 4(\mathrm{H}=0.0280 \mathrm{~m} ; \mathrm{T}=1.4 \mathrm{~s})$.
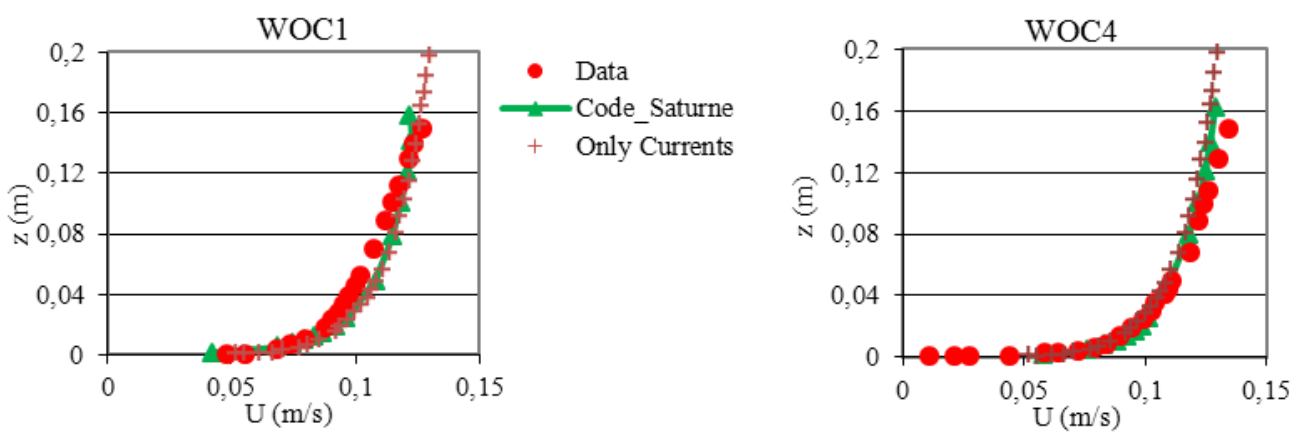

Figure 4. Mean horizontal velocity profile for waves opposing current: WOC1 $(H=0.0202 \mathrm{~m} ; \mathrm{T}=0.9 \mathrm{~s})$ and WOC4 $(H=0.0280 \mathrm{~m} ; \mathrm{T}=1.4 \mathrm{~s})$.

Figure 5 and figure 6 present the vertical profile of the Reynolds shear stress $R_{x z}$. The maximum value of this Reynolds stress decreases when compared with the only currents case, independently of the direction between the waves and the current. The superimposition of waves causes a reduction of Reynolds stresses not only near the 
bottom but also throughout the water depth. This general trend is also observed in the model results. In the case WFC4 a discrepancy in the Reynolds stresses near the surface in comparison to the experimental measurements can be seen. In particular, the reverse in sign of the measurements close to $z=0.06 \mathrm{~m}$ does not show up in the model simulations. The observed differences could be caused because the shear stress at the free surface due to the interface between air and water is not taken into account.
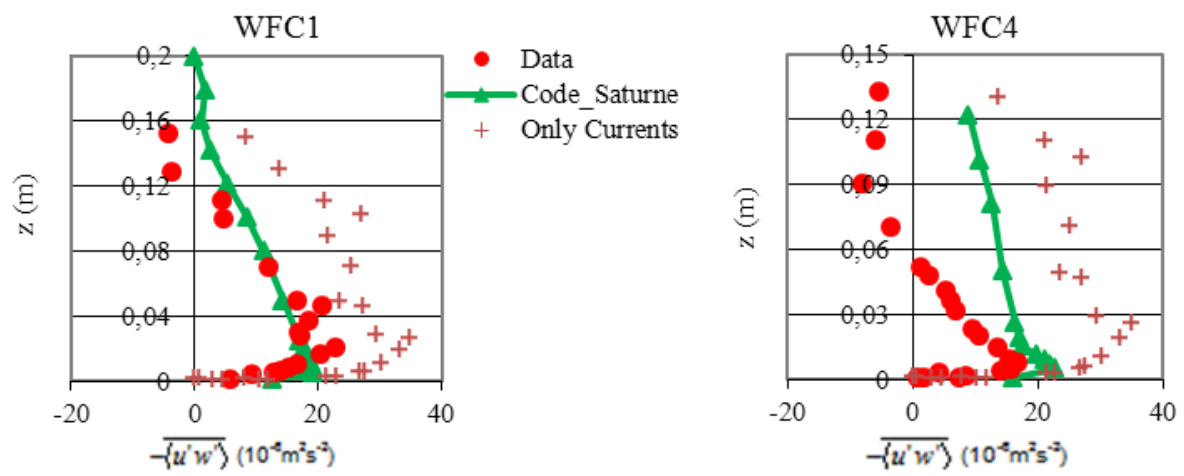

Figure 5. Shear stress vertical profile for waves following current: WFC1 ( $H=0.0202 \mathrm{~m} ; \mathrm{T}=0.9 \mathrm{~s})$ and $\mathrm{WFC} 4(\mathrm{H}=0.0280 \mathrm{~m} ; \mathrm{T}=1.4 \mathrm{~s})$.
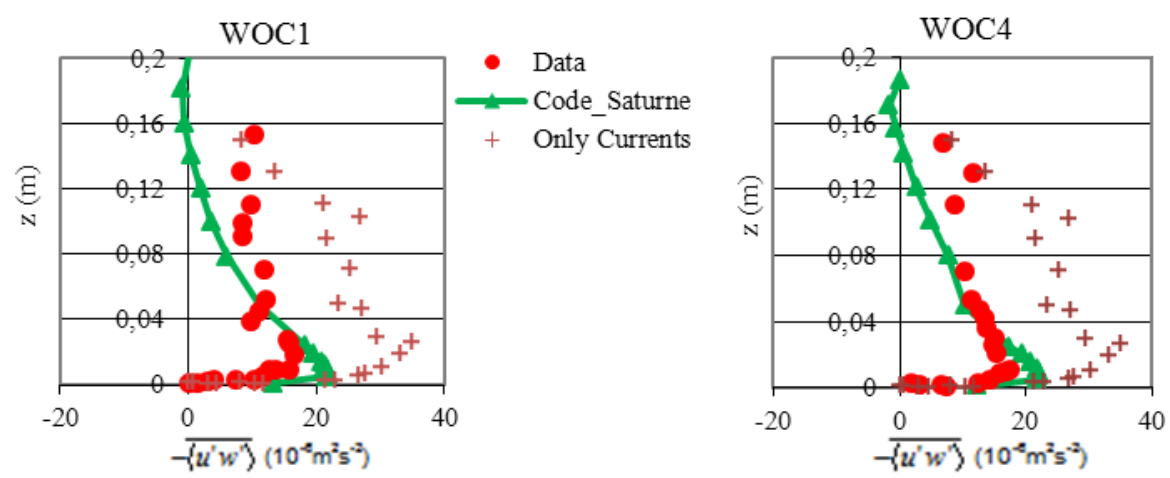

Figure 6. Shear stress vertical profile for waves opposing current: WOC1 $(H=0.0202 \mathrm{~m} ; \mathrm{T}=0.9 \mathrm{~s})$ and WOC4 $(H=0.0280 \mathrm{~m} ; \mathrm{T}=1.4 \mathrm{~s})$.

From the all tests made with code_Saturne, it can be confirmed that the model is able to reproduce quite well the waves-current interaction effects.

NEZU \& RODI (1986) did some experiments where they calculated from the measurements the vertical profile of turbulent viscosity in the only current case. Comparing with code_Saturne results, the same order of the dimensionless values was obtained (figure 7). The turbulent viscosity is zero either at the bottom or on the moving free surface. In code_Saturne, this behavior at the free surface was obtained due to the boundary condition imposed for the turbulent dissipation at the free surface (see Eq. 3). 


\section{XII ${ }^{\text {èmes }}$ Journées Nationales Génie Côtier - Génie Civil \\ Cherbourg, 12-14 juin 2012}

In order to get a simple parameterization of the turbulent viscosity development over the water column in this study, where waves and current interact, a dimensionless relation between the turbulent viscosity $\left(\mu_{t}\right)$, gravity $(g)$, mass transport velocity $(U)$, water depth $(h)$, wave period $(T)$ wave length $(L)$ and wave height $(H)$ was sought. After considering several possible dependences, it was found that the nondimensional turbulent viscosity $\mu_{t} /\left(g U T^{2}\right)$ at each relative elevation from the bottom (z/h) seems to decrease approximately linearly with the Ursell number $\left(H L^{2} / h^{3}\right)$, as illustrated in figure 8 , where the various variables correspond to the simulations made with code_Saturne.

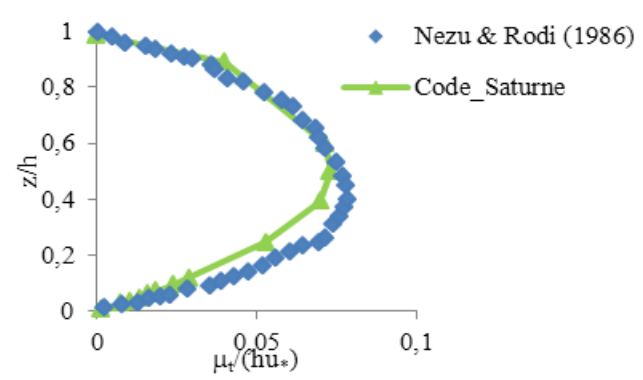

Figure 7. Comparison between measured and calculated eddy viscosity profile for an open channel flow with only current.

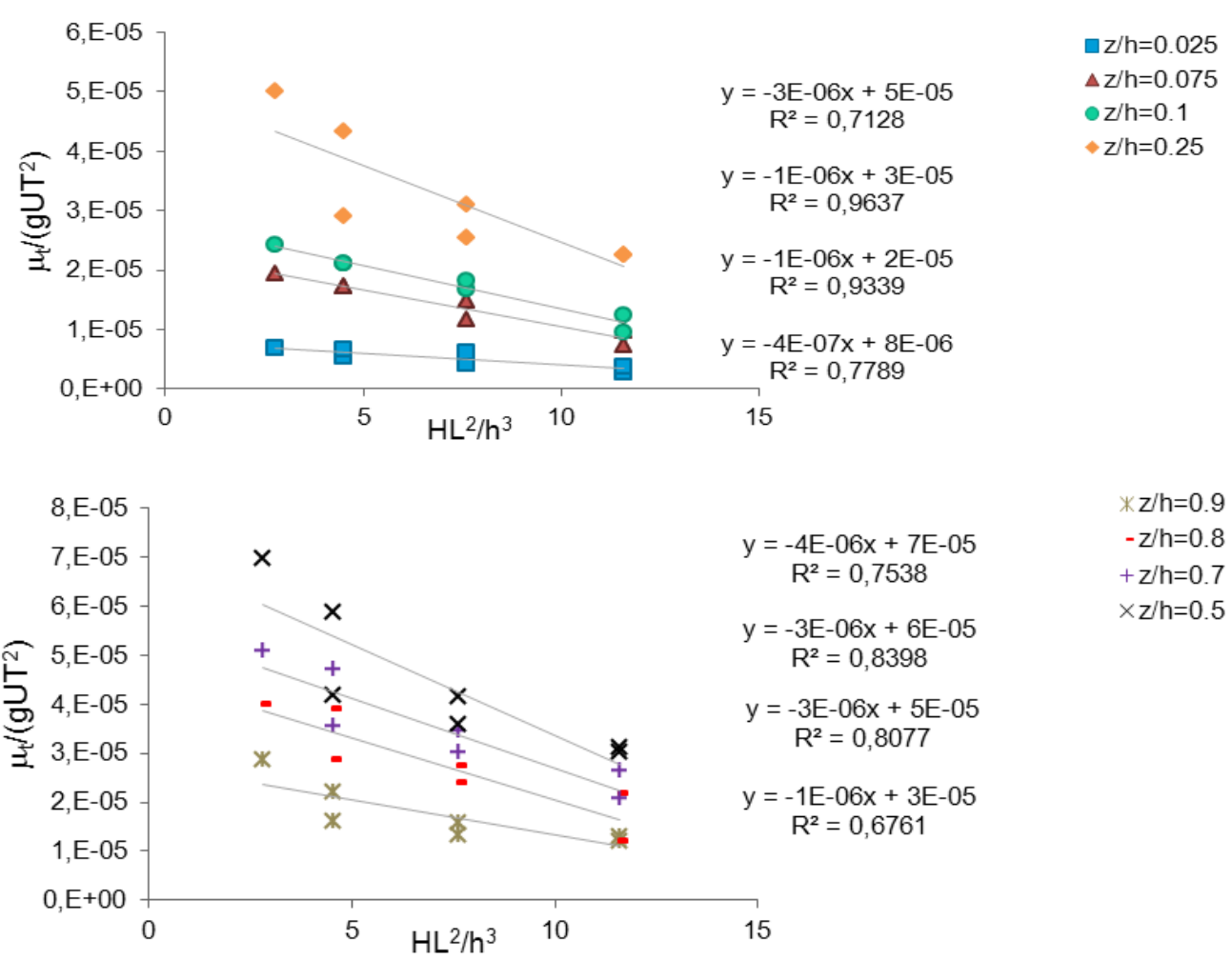

Figure 8. Variations of the turbulent viscosity value $\mu_{t} /\left(g U T^{2}\right)$ for each $\mathrm{z} / \mathrm{h}$ level as a function of the Ursell number $\mathrm{HL}^{2} / \mathrm{h}^{3}$. 


\section{Conclusions}

The modelling capabilities of code_Saturne model were verified for free surface flows in a combined wave-current environment. Data from UMEYAMA (2005) experiments was used to evaluate the model performances. Different test cases were available: only currents, only waves, waves following currents and waves opposing currents. The change of the vertical profile of the mean horizontal velocity caused by the presence of following or opposing waves on the mean flow has been well reproduced. When waves are superimposed in the same direction of the current there is a significant reduction of the mean velocities in the middle of the water column, while when waves have opposite direction of the current the shear of the velocity profile increases.

It was also explored the Reynolds stress profile changes for the combined wave and current environment. It was concluded that either when waves have the same direction of the current or the opposite direction, a change of the bed shear stress shows up. The superimposition of waves causes a reduction of turbulence stresses not only near the bottom but also throughout the water column.

Finally, the expression for the turbulent dissipation at the free surface, proposed by CELIK \& RODI (1984), imposed at the free surface has shown to be essential to reproduce correctly the vertical profiles of the Reynolds stresses and the turbulent viscosity.

\section{References}

ARCHAMBEAU F., MECHIOUA N., SAKIZ M. (2004). Code_Saturne: a finite volume code for the computation of turbulent incompressible flows - Industrial applications. International Journal on Finite Volumes, Vol. 1(1), pp 1-62.

CELIK I., RODI W. (1984). Simulation of free surface effects in turbulent channel flows. Physicochemical Hydrodynamics, Vol. 5, pp 217-227.

DEAN R.G., DALRYMPLE R.A. (1991). Water wave mechanics for engineers and scientists. Singapore, World Scientific Press. doi:10.1142/9789812385512

NEZU I., RODI W. (1986). Open channel flow measurements with a laser Doppler anemometer. Journal of Hydraulic Engineering, Vol. 112 (5), pp 335-355. doi:10.1061/(ASCE)0733-9429(1986)112:5(335)

OLABARRIETA M., MEDINA R., CASTANEDO S. (2010). Effects of wave-current interaction on the current profile. Coastal Engineering, Vol. 57 (7), pp 643-655. doi:10.1016/j.coastaleng.2010.02.003

SPEZIALE C.G., SARKAR S, GATSKI T.B. (1991). Modeling the pressure-strain correlation of turbulence: an invariant dynamical systems approach. Journal of Fluid Mechanics, Vol. 227, pp 245-272. doi:10.1017/S0022112091000101

UMEYAMA M. (2005). Reynolds stresses and velocity distributions in a wave-current coexisting environment. Journal of Waterway, Port, Coastal and Ocean Engineering, Vol. 131 (5), pp 203-212. doi:10.1061/(ASCE)0733-950X(2005)131:5(203) 